\title{
Generalizations of the strong Ekeland variational principle with a generalized distance in complete metric spaces
}

Somyot Plubtieng ${ }^{*}$ and Thidaporn Seangwattana

\section{"Correspondence:}

Somyotp@nu.ac.th

Department of Mathematics,

Faculty of Science, Naresuan

University, Phitsanulok, 65000,

Thailand

\begin{abstract}
In this paper, we prove a generalization of the strong Ekeland variational principle for a generalized distance (i.e., $u$-distance) on complete metric spaces. The result present in this paper extends and improves the corresponding result of Georgiev (J. Math. Anal. Appl. 131:1-21, 1988) and Suzuki (J. Math. Anal. Appl. 320:788-794, 2006).
\end{abstract}

Keywords: $u$-distance; complete metric space; Ekeland's variational principle

\section{Introduction}

In 1974, Ekeland [1] proved the following, which is called the Ekeland variational principle (for short, EVP).

Theorem 1.1 [1] Let $(X, d)$ be a complete metric space with metric $d$ and $f$ be a function from $X$ into $(-\infty,+\infty]$ which is proper lower semicontinuous bounded from below. Then for $u \in X$ and $\lambda>0$, there exists $v \in X$ such that

(P) $f(v) \leq f(u)-\lambda d(u, v)$;

(Q) $f(w)>f(v)-\lambda d(v, w)$ for every $w \neq v$.

Later, Takahashi [2] showed that this principle is equivalent to the Caristis fixed point theorem and nonconvex minimization theorem. In 1988, Georgiev [3] proved the following generalization of Theorem 1.1, which is called the strong Ekeland variational principle.

Theorem 1.2 [3] Let $X$ be a complete metric space with metric $d$ and $f: X \rightarrow(-\infty,+\infty$ ] be proper lower semicontinuous bounded from below. Then, for all $u \in X, \lambda>0$ and $\delta>0$, there exists $v \in X$ satisfying the following:

$(\mathrm{P})^{\prime} f(v)<f(u)-\lambda d(u, v)+\delta$;

(Q) $f(w)>f(v)-\lambda d(v, w)$ for every $w \in X \backslash\{v\}$;

(R) if a sequence $\left\{x_{n}\right\}$ in $X$ satisfies $\lim _{n \rightarrow \infty}\left(f\left(x_{n}\right)+\lambda d\left(v, x_{n}\right)\right)=f(v)$, then $\left\{x_{n}\right\}$ converges to $v$.

On the other hand, Kada et al. [4] introduced the concept of $w$-distance defined on a metric space and extended the Ekeland variational principle, the Kirk-Caristi fixed point theorem and the minimization theorem for $w$-distance. Recently, Suzuki $[5,6]$ introduced 
a more general concept than $w$-distance, which is called $\tau$-distance, and established the strong Ekeland variational principle for $\tau$-distance. Very recently, Ume [7] introduced a more generalized concept than $\tau$-distance, which is called $u$-distance, and proved a new minimization and a new fixed point theorem by using $u$-distance on a complete metric space.

In this paper, we prove the strong Ekeland variational principle for $u$-distance on a complete metric space. The results of this paper extend and generalize some results in Georgiev [3], Suzuki [5], Ansari [9] and Park [10].

\section{Preliminaries}

Throughout the paper, we denote by $\mathbb{N}$ the set of all positive integers, by $\mathbb{R}$ the set of real numbers, $\mathbb{R}_{+}=[0, \infty)$. Let us recall the following well-known definition of a $u$-distance.

Definition 2.1 ([8] and [7]) Let $X$ be a complete metric space with metric $d$. Then a function $p: X \times X \rightarrow \mathbb{R}_{+}$is called a $u$-distance on $X$ if there exists a function $\theta: X \times X \times$ $[0, \infty) \times[0, \infty) \rightarrow \mathbb{R}_{+}$such that

(u1) $p(x, z) \leq p(x, y)+p(y, z)$ for all $x, y, z \in X$;

(u2) $\theta(x, y, 0,0)=0, \theta(x, y, s, t) \geq \min \{s, t\}$ for all $x, y \in X$ and $s, t \in[0, \infty)$, and for any $x \in X$ and for every $\epsilon>0$, there exists $\delta>0$ such that $\left|s-s_{0}\right|<\delta,\left|t-t_{0}\right|<\delta$, $s, s_{0}, t, t_{0} \in[0, \infty)$ and $y \in X$ imply

$$
\left|\theta(x, y, s, t)-\theta\left(x, y, s_{0}, t_{0}\right)\right|<\epsilon
$$

(u3) $\lim _{n \rightarrow \infty} x_{n}=x$ and $\lim _{n \rightarrow \infty} \sup \left\{\theta\left(w_{n}, z_{n,}, p\left(w_{n}, x_{m}\right), p\left(z_{n}, x_{m}\right)\right): m \geq n\right\}=0$ imply $p(y, x) \leq \lim _{n \rightarrow \infty} \inf p\left(y, x_{n}\right)$ for all $y \in X ;$

(u4) $\lim _{n \rightarrow \infty} \sup \left\{p\left(x_{n}, w_{m}\right): m \geq n\right\}=0, \lim _{n \rightarrow \infty} \sup \left\{p\left(y_{n}, z_{m}\right): m \geq n\right\}=0$,

$\lim _{n \rightarrow \infty} \theta\left(x_{n}, w_{n}, s_{n}, t_{n}\right)=0$ and $\lim _{n \rightarrow \infty} \theta\left(y_{n}, z_{n}, s_{n}, t_{n}\right)=0$ imply

$\lim _{n \rightarrow \infty} \theta\left(w_{n}, z_{n}, s_{n}, t_{n}\right)=0$ or $\lim _{n \rightarrow \infty} \sup \left\{p\left(w_{m}, x_{n}\right): m \geq n\right\}=0$,

$\lim _{n \rightarrow \infty} \sup \left\{p\left(z_{m}, y_{n}\right): m \geq n\right\}=0, \lim _{n \rightarrow \infty} \theta\left(x_{n}, w_{n}, s_{n}, t_{n}\right)=0$ and

$\lim _{n \rightarrow \infty} \theta\left(y_{n}, z_{n}, s_{n}, t_{n}\right)=0$ imply $\lim _{n \rightarrow \infty} \theta\left(w_{n}, z_{n}, s_{n}, t_{n}\right)=0$;

(u5) $\lim _{n \rightarrow \infty} \theta\left(w_{n}, z_{n}, p\left(w_{n}, x_{n}\right), p\left(z_{n}, x_{n}\right)\right)=0$ and

$\lim _{n \rightarrow \infty} \theta\left(w_{n}, z_{n}, p\left(w_{n}, y_{n}\right), p\left(z_{n}, y_{n}\right)\right)=0$ imply $\lim _{n \rightarrow \infty} d\left(x_{n}, y_{n}\right)=0$ or

$\lim _{n \rightarrow \infty} \theta\left(a_{n}, b_{n}, p\left(x_{n}, a_{n}\right), p\left(x_{n}, b_{n}\right)\right)=0$ and

$\lim _{n \rightarrow \infty} \theta\left(a_{n}, b_{n}, p\left(y_{n}, a_{n}\right), p\left(y_{n}, b_{n}\right)\right)=0$ imply $\lim _{n \rightarrow \infty} d\left(x_{n}, y_{n}\right)=0$.

Proposition 2.2 [7] Let $p$ be a $u$-distance on a metric space $(X, d)$ and c be a positive real number. Then a function $q: X \times X \rightarrow \mathbb{R}_{+}$defined by $q(x, y)=c \cdot p(x, y)$ for every $x, y \in X$ is also a $u$-distance on $X$.

Lemma 2.3 [7] Let $(X, d)$ be a metric space and let $p$ be a $u$-distance on $X$. If $\left\{x_{n}\right\}$ is a $p$-Cauchy sequence, then $\left\{x_{n}\right\}$ is a Cauchy sequence.

Lemma 2.4 [7] Let $(X, d)$ be a metric space and $p$ be a u-distance on $X$. Suppose that a sequence $\left\{x_{n}\right\}$ of $X$ satisfies

$$
\lim _{n \rightarrow \infty} \sup \left\{p\left(x_{n}, x_{m}\right): m>n\right\}=0
$$


or

$$
\lim _{n \rightarrow \infty} \sup \left\{p\left(x_{m}, x_{n}\right): m>n\right\}=0
$$

Then, $\left\{x_{n}\right\}$ is a p-Cauchy sequence and $\left\{x_{n}\right\}$ is a Cauchy sequence.

\section{Main theorem}

Lemma 3.1 Let $X$ be a complete metric space and $p$ be a $u$-distance on $X$. If a sequence $\left\{x_{n}\right\}$ of $X$ satisfies $\lim _{n \rightarrow \infty} p\left(z, x_{n}\right)=0$ for some $z \in X$, then $\left\{x_{n}\right\}$ is a $p$-Cauchy sequence. Moreover, if a sequence $\left\{y_{n}\right\}$ of $X$ also satisfies $\lim _{n \rightarrow \infty} p\left(z, y_{n}\right)=0$, then $\lim _{n \rightarrow \infty} p\left(x_{n}, y_{n}\right)=0$. In particular, for $x, y, z \in X, p(z, x)=0$ and $p(z, y)=0$ imply $x=y$.

Proof Let $\theta$ be a function from $X \times X \times[0, \infty) \times[0, \infty)$ into $\mathbb{R}_{+}$satisfying (u1)-(u5). From $\lim _{n} p\left(z, x_{n}\right)=0$, it follows by (u2) that $\lim _{n \rightarrow \infty} \theta\left(z, z, p\left(z, x_{n}\right), p\left(z, x_{n}\right)\right)=0$. Therefore, $\left\{x_{n}\right\}$ is a $p$-Cauchy sequence.

Theorem 3.2 Let $X$ be a complete metric space and $T$ be a mapping from $X$ into itself. Suppose that there exists a $u$-distance $p$ on $X$ and $r \in[0,1) \operatorname{such}$ that $p\left(T x, T^{2} x\right) \leq r \cdot p(x, T x)$ for all $x \in X$. Assume that either of the following hold:

(i) If $\lim _{n \rightarrow \infty} \sup \left\{p\left(x_{n}, x_{m}\right): m>n\right\}=0, \lim _{n \rightarrow \infty} p\left(x_{n, T x_{n}}\right)=0$ and $\lim _{n \rightarrow \infty} p\left(x_{n}, y\right)=0$, then $T y=y$;

(ii) if $\left\{x_{n}\right\}$ and $\left\{T x_{n}\right\}$ converge to $y$, then $T y=y$;

(iii) $T$ is continuous.

Then, there exists $x_{0} \in X$ such that $T x_{0}=x_{0}$ and $p\left(x_{0}, x_{0}\right)=0$.

Proof It is the same as the proof of Theorem 1 in [5].

Lemma 3.3 Let $X$ be a complete metric space, $p$ be a $u$-distance on $X$ and $\phi$ be a function from $X \times X$ into $(-\infty, \infty]$ satisfying

(1) $\phi(x, z) \leq \phi(x, y)+\phi(y, z)$ for all $x, y, z \in X$;

(2) $\phi(x, \cdot): X \rightarrow(-\infty, \infty]$ is lower semicontinuous for any $x \in X$;

(3) there exists an $x_{0}$ such that $\inf _{y \in X} \phi\left(x_{0}, y\right)>-\infty$; and

(4) $\phi(x, y)=-\phi(y, x)$.

Define $M x=\{y \in X: \phi(x, y)+p(x, y) \leq 0\}$. Let $u \in X$ and $c \in \mathbb{R}_{+}$such that $\phi(x, u)<\infty$ for all $x \in X, M u \neq \emptyset$ and $c \geq \phi(x, u)-\inf _{y \in M u} \phi(u, y)$. Then a function $q: X \times X \rightarrow \mathbb{R}_{+}$defined by

$$
q(x, y)= \begin{cases}\phi(u, x)-\inf _{y \in M x} \phi(u, y) & \text { if } x \in M u \text { and } y \in M x, \\ c+p(x, y) & \text { if } x \notin M u \text { or } y \notin M x\end{cases}
$$

is a $u$-distance on $X$.

Proof Let $\eta$ be a function from $X \times X \times \mathbb{R}_{+} \times \mathbb{R}_{+}$into $\mathbb{R}_{+}$satisfying (u2)-(u5) for a $u$ distance. We note that $\phi(x, y)+\phi(y, z)+p(x, y)+p(y, z) \leq 0$ and $\phi(x, z)+p(x, z) \leq 0$. Thus, $y \in M x$ and $z \in M y$ imply $z \in M x$. If $x \in M u$ and $y \in M x$, then

$$
\begin{aligned}
p(x, y) & \leq \phi(y, x) \leq q(x, y)=\phi(y, x)-\inf _{y \in M x} \phi(x, y) \\
& \leq \phi(x, u)-\inf _{y \in M u} \phi(x, y) \leq c .
\end{aligned}
$$


Therefore, $p(x, y) \leq q(y, x) \leq c+p(x, y)$ for all $x, y \in X$. To complete the proof, we will show $(\mathrm{u} 1)_{q},(\mathrm{u} 3)_{q, \eta},(\mathrm{u} 4)_{q, \eta}$ and (u5) $)_{q, \eta}$. Let $x, y$ and $z$ be fixed elements in $X$. In the case $x \in M u$, $y \in M x, y \in M u$ and $z \in M y$, we have $z \in M x$ and hence $q(x, z)=q(x, y) \leq q(x, y)+q(y, z)$. In the other case, we note that

$$
\begin{aligned}
q(x, z) & \leq c+p(x, z) \leq c+p(x, y)+p(y, z) \\
& \leq 2 c+p(x, y)+p(y, z) \\
& =q(x, y)+q(y, z) .
\end{aligned}
$$

This shows $(\mathrm{u} 1)_{q}$.

We next suppose that $\lim _{n \rightarrow \infty} x_{n}=x$ and $\lim _{n \rightarrow \infty} \sup \left\{\eta\left(w_{n}, z_{n}, q\left(w_{n}, x_{m}\right), q\left(z_{n}, x_{m}\right)\right): m \geq\right.$ $n\}=0$ and fix $w \in X$. Since $\lim _{n \rightarrow \infty} \sup \left\{\theta\left(w_{n}, z_{n}, p\left(w_{n}, x_{m}\right), p\left(z_{n}, x_{m}\right)\right): m \geq n\right\}=0$, we have $p(w, x) \leq \liminf _{n \rightarrow \infty} p\left(w, x_{n}\right)$ for all $y \in X$.

In the case that $w \in M u$ and there exists a subsequence $\left\{x_{n_{k}}\right\}$ of $\left\{x_{n}\right\}$ such that $x_{n_{k}} \in M w$ for all $k \in \mathbb{N}$, we have

$$
\begin{aligned}
\phi(w, x)+p(w, x) & \leq \lim _{n \rightarrow \infty} \inf \phi\left(w, x_{n}\right)+\lim _{n \rightarrow \infty} p\left(w, x_{n}\right) \\
& \leq \lim _{n \rightarrow \infty} \inf \left(\phi\left(w, x_{n}\right)+p\left(w, x_{n}\right)\right) \\
& \leq \lim _{k \rightarrow \infty} \inf \left(\phi\left(w, x_{n_{k}}\right)+p\left(w, x_{n_{k}}\right)\right) \\
& \leq 0,
\end{aligned}
$$

and so $x \in M u$. Hence

$$
q(w, x)=\phi(u, w)-\inf _{x \in M w} \phi(u, x)=\lim _{k \rightarrow \infty} q\left(w, x_{n_{k}}\right)=\lim _{n \rightarrow \infty} \inf q\left(w, x_{n}\right) .
$$

In the other case, we obtain

$$
\begin{aligned}
q(w, x) & \leq c+p(w, x) \leq \lim _{n \rightarrow \infty} \inf \left(c+p\left(w, x_{n}\right)\right) \\
& =\lim _{n \rightarrow \infty} \inf q\left(w, x_{n}\right) .
\end{aligned}
$$

This shows $(\mathrm{u} 3)_{q, \eta}$. We will show that $q$ satisfies $(\mathrm{u} 4)_{q, \eta}$.

Case I: Suppose that $\lim _{n \rightarrow \infty} \sup \left\{q\left(x_{n}, w_{m}\right): m \geq n\right\}=0, \lim _{n \rightarrow \infty} \sup \left\{q\left(y_{n}, z_{m}\right): m \geq n\right\}=$ $0, \lim _{n \rightarrow \infty} \eta\left(x_{n}, w_{n}, s_{n}, t_{n}\right)=0$, and $\lim _{n \rightarrow \infty} \eta\left(y_{n}, z_{n}, s_{n}, t_{n}\right)=0$.

In the case $x_{n} \in M u$ and $w_{m} \in M x_{n}$, we note that $q\left(x_{n}, w_{n}\right)=\phi\left(u, x_{n}\right)-\inf _{w_{m} \in M x_{n}} \phi\left(u, w_{m}\right)$. Since $\phi\left(x_{n}, w_{m}\right)+p\left(x_{n}, w_{n}\right) \leq 0$, it follows that

$$
\begin{aligned}
p\left(x_{n}, w_{m}\right) & \leq-\phi\left(x_{n}, w_{n}\right)=\phi\left(w_{m}, x_{n}\right) \\
& \leq \phi\left(w_{m}, u\right)+\phi\left(u, x_{n}\right) \\
& =\phi\left(u, x_{n}\right)-\phi\left(u, w_{m}\right) \\
& \leq \phi\left(u, x_{n}\right)-\inf _{w_{m} \in M x_{n}} \phi\left(u, w_{m}\right)=q\left(x_{n}, w_{m}\right) .
\end{aligned}
$$


Thus, we have $p\left(x_{n}, w_{m}\right) \leq q\left(x_{n}, w_{m}\right)$. This implies that $\sup _{m \geq n} p\left(x_{n}, w_{n}\right) \leq \sup _{m \geq n} q\left(x_{n}, w_{m}\right)$.

Take $n \rightarrow \infty$, so

$$
0 \leq \lim _{n \rightarrow \infty} \sup p\left(x_{n}, w_{m}\right) \leq \lim _{n \rightarrow \infty} \sup q\left(x_{n}, w_{m}\right)=0
$$

and therefore $\lim _{n \rightarrow \infty} \sup p\left(x_{n}, w_{m}\right)=0$.

Similarly, if $y_{n} \in M u$ and $z_{m} \in M y_{n}$, then $\lim _{n \rightarrow \infty} \sup p\left(y_{n}, z_{m}\right)=0$.

We note that $\lim _{n \rightarrow \infty} \theta\left(x_{n}, w_{n}, s_{n}, t_{n}\right)=0=\lim _{n \rightarrow \infty} \theta\left(y_{n}, z_{n}, s_{n}, t_{n}\right)$ and hence

$$
\lim _{n \rightarrow \infty} \eta\left(w_{n}, z_{n}, s_{n}, t_{n}\right)=0
$$

In the case $x_{n} \neq M u$ or $w_{m} \neq M x_{n}$, we note that $p\left(x_{n}, w_{m}\right) \leq c+p\left(x_{n}, w_{m}\right)=q\left(x_{n}, w_{m}\right)$. Thus, we have $p\left(x_{n}, w_{m}\right) \leq q\left(x_{n}, w_{m}\right)$. This implies that $\sup _{m \geq n} p\left(x_{n}, w_{m}\right) \leq \sup _{m \geq n} q\left(x_{n}\right.$, $\left.w_{m}\right)$. Taking $n \rightarrow \infty$, we obtain

$$
0 \leq \lim _{n \rightarrow \infty} \sup p\left(x_{n}, w_{m}\right) \leq \lim _{n \rightarrow \infty} \sup q\left(x_{n}, w_{m}\right)=0
$$

and therefore $\lim _{n \rightarrow \infty} \sup p\left(x_{n}, w_{n}\right)=0$. Similarly as above, if $y_{n} \neq M u$ and $z_{m} \neq M y_{n}$, then $\lim _{n \rightarrow \infty} \sup p\left(y_{n}, z_{m}\right)=0$. We note that $\lim _{n \rightarrow \infty} \theta\left(x_{n}, w_{n}, s_{n}, t_{n}\right)=0=\lim _{n \rightarrow \infty} \theta\left(y_{n}, z_{n}, s_{n}, t_{n}\right)$ and hence $\lim _{n \rightarrow \infty} \eta\left(w_{n}, z_{n}, s_{n}, t_{n}\right)=0$.

Case II: Suppose that $\lim _{n \rightarrow \infty} \sup \left\{q\left(w_{m}, x_{n}\right): m \geq n\right\}=0, \lim _{n \rightarrow \infty} \sup \left\{q\left(z_{m}, y_{n}\right): m \geq\right.$ $n\}=0, \lim _{n \rightarrow \infty} \eta\left(x_{n}, w_{n}, s_{n}, t_{n}\right)=0$ and $\lim _{n \rightarrow \infty} \eta\left(y_{n}, z_{n}, s_{n}, t_{n}\right)=0$. Similarly as in Case I, we can show that $\lim _{n \rightarrow \infty} \eta\left(w_{n}, z_{n}, s_{n}, t_{n}\right)=0$. This shows $(\mathrm{u} 4)_{q, \eta}$. We will show that $q$ satisfies (u5) $q, \eta$.

Case I: Suppose that $\lim _{n \rightarrow \infty} \eta\left(w_{n}, z_{n}, q\left(x_{n}, w_{n}\right), q\left(x_{n}, z_{n}\right)\right)=0$ and $\lim _{n \rightarrow \infty} \eta\left(w_{n}, z_{n}, q\left(y_{n}\right.\right.$, $\left.\left.w_{n}\right), q\left(y_{n}, z_{n}\right)\right)=0$. In the case $x_{n} \in M u$ and $w_{n}, z_{n} \in M x_{n}$, we note that $q\left(x_{n}, w_{n}\right)=\phi\left(u, x_{n}\right)-$ $\inf _{w_{n} \in M x_{n}} \phi\left(u, w_{n}\right)$ and hence $q\left(x_{n}, z_{n}\right)=\phi\left(u, x_{n}\right)-\inf _{z_{n} \in M x_{n}} \phi\left(u, z_{n}\right)$. Thus, we have

$$
\begin{aligned}
\theta\left(w_{n}, z_{n}, p\left(x_{n}, w_{n}\right), p\left(x_{n}, z_{n}\right)\right) \leq & \theta\left(w_{n}, z_{n}, \phi\left(z_{n}, x_{n}\right), \phi\left(z_{n}, x_{n}\right)\right) \\
\leq & \theta\left(w_{n}, z_{n}, \phi\left(w_{n}, u\right)+\phi\left(u, x_{n}\right), \phi\left(z_{n}, u\right)+\phi\left(u, x_{n}\right)\right) \\
= & \theta\left(w_{n}, z_{n}, \phi\left(u, x_{n}\right)-\phi\left(u, w_{n}\right), \phi\left(u, x_{n}\right)-\phi\left(u, z_{n}\right)\right) \\
\leq & \theta\left(w_{n}, z_{n}, \phi\left(u, x_{n}\right)-\inf _{w_{n} \in M x_{n}} \phi\left(u, w_{n}\right), \phi\left(u, x_{n}\right)\right. \\
& \left.-\inf _{z_{n} \in M x_{n}} \phi\left(u, z_{n}\right)\right) \\
= & \eta\left(w_{n}, z_{n}, q\left(x_{n}, w_{n}\right), q\left(x_{n}, z_{n}\right)\right) .
\end{aligned}
$$

Taking $n \rightarrow \infty$, we have

$$
0 \leq \lim _{n \rightarrow \infty} \theta\left(w_{n}, z_{n}, p\left(x_{n}, w_{n}\right), p\left(x_{n}, z_{n}\right)\right) \leq \lim _{n \rightarrow \infty} \eta\left(w_{n}, z_{n}, q\left(x_{n}, w_{n}\right), q\left(x_{n}, z_{n}\right)\right)=0
$$

Therefore $\lim _{n \rightarrow \infty} \theta\left(w_{n}, z_{n}, p\left(x_{n}, w_{n}\right), p\left(x_{n}, z_{n}\right)\right)=0$. Similarly, if $y_{n} \in M u$ and $z_{n}, w_{n} \in M y_{n}$, then $\lim _{n \rightarrow \infty} \theta\left(w_{n}, z_{n}, p\left(y_{n}, w_{n}\right), p\left(y_{n}, z_{n}\right)\right)=0$. In the case $x_{n} \neq M u$ or $w_{n}, z_{n} \neq M x_{n}$, we have $q\left(x_{n}, w_{n}\right)=c+p\left(x_{n}, w_{n}\right)$ and $q\left(x_{n}, z_{n}\right)=c+p\left(x_{n}, z_{n}\right)$. Since $p$ is a $u$-distance, we have 


$$
\begin{aligned}
& \lim _{n \rightarrow \infty} d\left(x_{n}, y_{n}\right)=0 \text {. Hence } \\
& \begin{aligned}
\theta\left(w_{n}, z_{n}, c+p\left(x_{n}, w_{n}\right), c+p\left(x_{n}, z_{n}\right)\right) & \leq \theta\left(w_{n}, z_{n}, c+p\left(x_{n}, w_{n}\right), c+p\left(x_{n}, z_{n}\right)\right) \\
& \leq \eta\left(w_{n}, z_{n}, q\left(x_{n}, w_{n}\right), q\left(x_{n}, z_{n}\right)\right) .
\end{aligned}
\end{aligned}
$$

Take $n \rightarrow \infty$, thus

$$
0 \leq \lim _{n \rightarrow \infty} \theta\left(w_{n}, z_{n}, p\left(x_{n}, w_{n}\right), p\left(x_{n}, z_{n}\right)\right) \leq \lim _{n \rightarrow \infty} \eta\left(w_{n}, z_{n}, q\left(x_{n}, w_{n}\right), q\left(x_{n}, z_{n}\right)\right)=0
$$

Therefore $\lim _{n \rightarrow \infty} \theta\left(w_{n}, z_{n}, p\left(x_{n}, w_{n}\right), p\left(x_{n}, z_{n}\right)\right)=0$. Similarly, if $y_{n} \neq M u$ or $w_{n}, z_{n} \neq M y_{n}$, then $\lim _{n \rightarrow \infty} \theta\left(w_{n}, z_{n}, p\left(y_{n}, w_{n}\right), p\left(y_{n}, z_{n}\right)\right)=0$. Since $p$ is a $u$-distance, we have $\lim _{n \rightarrow \infty} d\left(x_{n}\right.$, $\left.y_{n}\right)=0$.

Case II: Suppose that $\lim _{n \rightarrow \infty} \eta\left(w_{n}, z_{n}, q\left(w_{n}, x_{n}\right), q\left(z_{n}, x_{n}\right)\right)=0$ and $\lim _{n \rightarrow \infty} \eta\left(w_{n}, z_{n}, q\left(w_{n}\right.\right.$, $\left.\left.y_{n}\right), q\left(z_{n}, y_{n}\right)\right)=0$. Similarly as in Case I, we can show that $\lim _{n \rightarrow \infty} d\left(x_{n}, y_{n}\right)=0$. This shows $(\mathrm{u} 5)_{q, \eta}$.

Proposition 3.4 Let $X$ be a complete metric space, $p$ be a $u$-distance on $X$ and $\phi$ be a function from $X \times X$ into $(-\infty, \infty]$ satisfying

(1) $\phi(x, z) \leq \phi(x, y)+\phi(y, z)$ for all $x, y, z \in X$;

(2) $\phi(x, \cdot): X \rightarrow(-\infty, \infty]$ is lower semicontinuous for any $x \in X$;

(3) there exists an $x_{0}$ such that $\inf _{y \in X} \phi\left(x_{0}, y\right)>-\infty$; and

(4) $\phi(x, y)=-\phi(y, x)$.

Define $M x=\{y \in X: \phi(x, y)+p(x, y) \leq 0\}$ for all $x \in X$. Then, for each $u \in X$ with $M u \neq \emptyset$, there exists $x_{0} \in M u$ such that $M x_{0} \subset\left\{x_{0}\right\}$. In particular, there exists $y_{0} \in X$ such that $M y_{0} \subset\left\{y_{0}\right\}$.

Proof Let $u \in X$ with $M u \neq \emptyset$. We have $u_{1} \in M u$ by $\phi\left(u, u_{1}\right)<\infty$. If $M u=\emptyset$, the assertion holds. Suppose that $M u_{1} \neq \emptyset$ and $M x \cap(X\{x\}) \neq \emptyset$ for all $x \in M u_{1}$. Let $u_{2} \in M u_{1}$. We know that $\phi(x, y) \leq 0$ for all $x \in X$ and $y \in M x$, we define a mapping $T: X \rightarrow X$ as follows: For each $x \in M u_{1}, T x$ satisfies $T x \in M x, T x \neq x$ and

$$
\phi\left(u_{1}, T x\right) \leq \frac{\phi\left(u_{1}, x\right)+\inf _{y \in M x} \phi\left(u_{1}, y\right)}{2} .
$$

For each $x \notin M u_{1}$, define $T x=u_{2} \neq x$. We also define a function $q: X \times X \rightarrow \mathbb{R}^{+}$by

$$
q(x, y)= \begin{cases}\phi(u, x)-\inf _{y \in M x} \phi\left(u_{1}, y\right) & \text { if } x \in M u_{1} \text { and } y \in M x, \\ 2 \phi\left(u, u_{1}\right)-2 \inf _{w \in M u_{1}} \phi(u, w)+1+p(x, y) & \text { if } x \notin M u_{1} \text { or } y \notin M x .\end{cases}
$$

By Lemma 3.3, we have $q$ is a $u$-distance on $X$. Since $y \in M y$ and $z \in M y$, it follows by Lemma 3.3 that $z \in M x$. Hence $T x \in M u_{1}$ and $M T x \subset M x$ for all $x \in M u_{1}$. If $x \in M u_{1}$, we obtain

$$
\begin{aligned}
q\left(T x, T^{2} x\right) & =\phi\left(u_{1}, T x\right)-\inf _{y \in M T x} \phi\left(u_{1}, y\right) \\
& \leq \frac{\phi\left(u_{1}, x\right)+\inf _{y \in M x} \phi\left(u_{1}, y\right)}{2}-\inf _{y \in M x} \phi\left(u_{1}, y\right) \\
& =\frac{q(x, T x)}{2} .
\end{aligned}
$$


If $x \notin M u_{1}$,

$$
\begin{aligned}
q\left(T x, T^{2} x\right) & =q\left(u_{2}, T u_{2}\right)=\phi\left(u_{1}, u_{2}\right)-\inf _{T u_{2} \in M u_{2}} \phi\left(u_{1}, T u_{2}\right) \\
& \leq \phi\left(u, u_{1}\right)-\inf _{T u_{1}} \phi\left(u, T u_{1}\right) \\
& \leq \frac{q\left(x, u_{2}\right)}{2}=\frac{q(x, T x)}{2} .
\end{aligned}
$$

We will show (i) in Theorem 3.2. Suppose that $\lim _{n \rightarrow \infty} \sup \left\{q\left(x_{n}, x_{m}\right): m>n\right\}=0$ and $\lim _{n \rightarrow \infty} q\left(x_{n}, y\right)=0$. We may assume $x_{n} \in M u_{1}$ and $y \in M x_{n}$ for all $n \in \mathbb{N}$ by the definition of $q$. Then $y \in M u_{1}$ and hence $T y \in M y \subset M x_{n}$. By Lemma 2.4 we have $\lim _{n \rightarrow \infty} q\left(x_{n}, T y\right)=$ $\lim _{n \rightarrow \infty} q\left(x_{n}, y\right)=0$ and $T y=y$. Hence, by Theorem 3.2, $T$ has a fixed point. This is a contradiction. So, there is $x_{0} \in M u_{1} \subset M u$ such that $M x_{0} \subset\left\{x_{0}\right\}$.

Theorem 3.5 Let $X$ be a complete metric space, $p$ be a u-distance on $X$ and $\phi$ be a function from $X \times X$ into $(-\infty, \infty]$ satisfying

(1) $\phi(x, z) \leq \phi(x, y)+\phi(y, z)$ for all $x, y, z \in X$

(2) $\phi(x, \cdot): X \rightarrow(-\infty, \infty]$ is lower semicontinuous for any $x \in X$;

(3) there exists an $x_{0}$ such that $\inf _{y \in X} \phi\left(x_{0}, y\right)>-\infty$; and

(4) $\phi(x, y)=-\phi(y, x)$.

Then the following hold:

(A) For each $u \in X$, there exists $v \in X$ such that $\phi(u, v) \leq 0$ and $\phi(v, w)+p(v, w)>0$ for all $w \in X \backslash\{v\}$;

(B) For each $\lambda>0$ and $u \in X$ with $p(u, u)=0$, there exists $v \in X$ such that $\phi(u, v)+\lambda p(u, v) \leq 0$ and $\phi(v, w)+\lambda p(v, w)>0$ for all $w \in X \backslash\{v\}$.

Proof We will show that (A). For each $x \in X$, we define $M x$ as in Proposition 3.4. If $M u=$ $\emptyset$, we have $u$ that satisfies $\phi(u, w)+p(u, w)>0$ for all $w \in X$ with $w \neq u$. If $M u \neq \emptyset$ and there exists $v \in M u$, then it follows by Proposition 3.4 that $M v \subset\{v\}$. Since $v \in M u$ implies $\phi(u, v) \leq 0$ and $M v \subset\{v\}$, this shows that $\phi(v, w)+p(v, w)>0$ for all $w \in X$ with $w \neq v$.

We will show that (B). By Proposition 2.2, we note that $\lambda p$ is a $u$-distance. We define $M x=\{y \in X: \phi(x, y)+\lambda p(x, y) \leq 0\}$ for all $x \in X$. Since $p(u, u)=0$, we have $M u \neq \emptyset$, and hence there exists $v \in M u$ such that $M v \subseteq\{v\}$ by Proposition 3.4. Therefore $v$ satisfies $\phi(u, v)+\lambda p(u, v) \leq 0$ and $\phi(v, w)+\lambda p(v, w)>0$ for all $w \in X$ with $w \neq v$. This completes the proof.

Remark 3.6 By setting $\phi(x, y)=f(y)-f(x)$, where $f: X \rightarrow \mathbb{R}$ is lower semicontinuous bounded below, and letting $p$ be a $\tau$-distance in Theorem 3.5, we obtain the Ekeland variational principle proved by Suzuki [5].

Theorem 3.7 Let $X$ be a complete metric space, $p$ be a $u$-distance on $X$ and $\phi$ be a function from $X \times X$ into $(-\infty, \infty]$ satisfying

(1) $\phi(x, z) \leq \phi(x, y)+\phi(y, z)$ for all $x, y, z \in X$;

(2) $\phi(x, \cdot): X \rightarrow(-\infty, \infty]$ is lower semicontinuous for any $x \in X$;

(3) there exists an $x_{0}$ such that $\inf _{y \in X} \phi\left(x_{0}, y\right)>-\infty$; and

(4) $\phi(x, y)=-\phi(y, x)$.

Let $u \in X$ with $p(u, u)=0$. Then $\lambda>0$ and $\delta>0$, there exists $v \in X$ satisfying the following: 
(i) $\phi(u, v) \leq 0$;

(ii) $\phi(u, v)+\lambda p(u, v)<\delta$;

(iii) $\phi(v, w)+\lambda p(v, w)>0$ for all $w \in X \backslash\{v\}$;

(iv) if a sequence $\left\{x_{n}\right\}$ in $X$ satisfies $\lim _{n}\left(\phi\left(v, x_{n}\right)+\lambda p\left(v, x_{n}\right)\right)=0$, then $\left\{x_{n}\right\}$ is $p$-Cauchy, $\lim _{n} x_{n}=v$ and $p(v, v)=\lim _{n} p\left(v, x_{n}\right)=0$.

Proof In the case $\phi(v, u)=\infty$, (i) and (ii) hold for all $v \in X$. We also note that (iii) and (iv) do not depend on $\phi(v, u)$. In the case $\phi(v, u)<\infty$, set $\lambda^{\prime} \in(0, \lambda)$ satisfying

$$
\frac{\lambda-\lambda^{\prime}}{\lambda^{\prime}}\left(\phi(u, v)-\inf _{x \in X} \phi(v, x)\right)<\delta .
$$

By Theorem 3.5(B), there exists $v \in X$ such that $\phi(u, v)+\lambda^{\prime} p(u, v) \leq 0$ and $\phi(v, w)+$ $\lambda^{\prime} p(v, w)>0$ for all $w \in X \backslash\{v\}$. Thus, we have

$$
\begin{aligned}
\phi(u, v) & =\left(1+\frac{\lambda-\lambda^{\prime}}{\lambda^{\prime}}\right) \phi(u, v)-\left(\frac{\lambda-\lambda^{\prime}}{\lambda^{\prime}}\right) \phi(u, v) \\
& \leq\left(1+\frac{\lambda-\lambda^{\prime}}{\lambda^{\prime}}\right)\left(-\lambda^{\prime} p(u, v)\right)-\left(\frac{\lambda-\lambda^{\prime}}{\lambda^{\prime}}\right) \phi(u, v) \\
& =-\lambda^{\prime} p(u, v)-\left(\lambda-\lambda^{\prime}\right)(p(u, v))-\left(\frac{\lambda-\lambda^{\prime}}{\lambda^{\prime}}\right) \phi(u, v) \\
& =-\lambda p(u, v)-\left(\frac{\lambda-\lambda^{\prime}}{\lambda^{\prime}}\right) \phi(u, v) \\
& \leq-\lambda p(u, v)+\left(\frac{\lambda-\lambda^{\prime}}{\lambda^{\prime}}\right) \phi(u, v)+\left(\frac{\lambda-\lambda^{\prime}}{\lambda^{\prime}}\right) \inf _{x \in X} \phi(x, v) \\
& =-\lambda p(u, v)+\left(\frac{\lambda-\lambda^{\prime}}{\lambda^{\prime}}\right)\left(\phi(u, v)-\inf _{x \in X} \phi(v, x)\right) \\
& <-\lambda p(u, v)+\delta .
\end{aligned}
$$

Therefore, $\phi(u, v)+\lambda p(u, v)<\delta$. For $w \in X \backslash\{v\}$, we note that

$$
\phi(v, w)>-\lambda^{\prime} p(v, w) \geq-\lambda p(v, w)
$$

So, $\phi(v, w)+\lambda p(v, w)>0$. Finally, we will show that (iv). Suppose that a sequence $\left\{x_{n}\right\}$ in $X$ satisfies $\lim _{n}\left(\phi\left(v, x_{n}\right)+\lambda p\left(v, x_{n}\right)\right)=0$. We note that $\phi(v, w)+\lambda^{\prime} p(v, w) \geq 0$ for all $w \in X$. We have

$$
\begin{aligned}
\lim _{n \rightarrow \infty} \sup p\left(v, x_{n}\right) & =\lim _{n \rightarrow \infty} \sup \left(\frac{\lambda-\lambda^{\prime}}{\lambda-\lambda^{\prime}}\right) p\left(v, x_{n}\right) \\
& =\lim _{n \rightarrow \infty} \frac{\lambda p\left(v, x_{n}\right)-\lambda^{\prime} p\left(v, x_{n}\right)}{\lambda-\lambda^{\prime}} \\
& \leq \lim _{n \rightarrow \infty} \frac{\lambda p\left(v, x_{n}\right)-\phi\left(v, x_{n}\right)}{\lambda-\lambda^{\prime}} \\
& \leq \lim _{n \rightarrow \infty} \frac{\lambda p\left(v, x_{n}\right)+\phi\left(v, x_{n}\right)}{\lambda-\lambda^{\prime}} \\
& =0 .
\end{aligned}
$$


By Lemma 3.1, $\left\{x_{n}\right\}$ is a $p$-Cauchy sequence. From Lemma 2.3, therefore $\left\{x_{n}\right\}$ is a Cauchy sequence. By the completeness of $X,\left\{x_{n}\right\}$ converges to some point $x \in X$. From (u3), we have $p(\nu, x)=0$ and so

$$
\begin{aligned}
\phi(v, x) & \leq \lim _{n \rightarrow \infty} \inf \phi\left(v, x_{n}\right) \\
& \leq \lim _{n \rightarrow \infty}\left(\phi\left(v, x_{n}\right)+\lambda p\left(v, x_{n}\right)\right)=0 .
\end{aligned}
$$

Thus, if $v \neq x$, then we have

$$
\phi(\nu, x)>-\lambda^{\prime} p(\nu, x) \geq \phi(v, x) .
$$

This is a contradiction. Hence, we obtain $v=x$.

Remark 3.8 By setting $\phi(x, y)=f(y)-f(x)$, where $f: X \rightarrow \mathbb{R}$ is lower semicontinuous bounded below. Let $p$ be a $\tau$-distance in Theorem 3.7, we obtain the strong Ekeland variational principle proved by Suzuki [6].

\section{Competing interests}

The authors declare that they have no competing interests.

\section{Authors' contributions}

All authors read and approved the final manuscript.

\section{Acknowledgements}

The authors would like to thank the Thailand Research Fund (TRF) for supporting by permit money of investment under of The Royal Golden Jubilee Ph.D. Program (RGJ-Ph.D.), Thailand.

Received: 28 September 2012 Accepted: 28 February 2013 Published: 21 March 2013

\section{References}

1. Ekeland, I: On the variational principle. J. Math. Anal. Appl. 47, 324-353 (1974)

2. Takahashi, W: Existence theorems generalizing fixed point theorems for multivalued mappings. In: Thera, MA, Baillon, JB (eds.) Fixed Point Theory and Applications. Pitman Res. Notes in Math. Ser., vol. 252, pp. 397-406. Longman, Harlow (1991)

3. Georgiev, PG: The strong Ekeland variational principle, the strong drop theorem and applications. J. Math. Anal. Appl. $131,1-21(1988)$

4. Kada, O, Suzuki, T, Takahashi, W: Nonconvex minimization theorems and fixed point theorems in complete metric spaces. Math. Jpn. 44, 381-391 (1996)

5. Suzuki, T: Generalized distance and existence theorem in complete metric spaces. J. Math. Anal. Appl. 253, 440-458 (2001)

6. Suzuki, T: The strong Ekeland variational principle. J. Math. Anal. Appl. 320, 787-794 (2006)

7. Ume, JS: Existence theorem for generalized distance on complete metric spaces. Fixed Point Theory Appl. 2010 $397150(2010)$

8. Hirunworakit, S, Petrot, N: Some fixed point theorems for contractive multivalued mappings induced by generalized distance in metric spaces. Fixed Point Theory Appl. (2011). doi:10.1186/1687-1812-2011-78

9. Ansari, QH: Vectorial form of Ekeland-type variational principle with applications to vector equilibrium problems and fixed point theory. J. Math. Anal. Appl. 334, 561-575 (2007)

10. Park, S: On generalizations of the Ekeland-type variational principle. Nonlinear Anal. 39, 881-889 (2000)

doi:10.1186/1029-242X-2013-120

Cite this article as: Plubtieng and Seangwattana: Generalizations of the strong Ekeland variational principle with a generalized distance in complete metric spaces. Journal of Inequalities and Applications 2013 2013:120. 